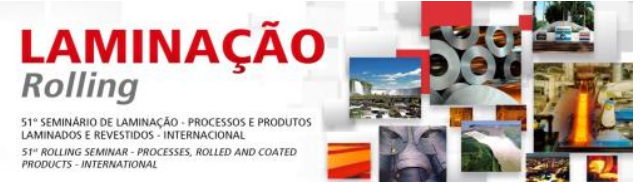

\title{
AVALIAÇÃO DO EFEITO DO CORTE POR CISALHAMENTO NA CAPACIDADE DE FLANGEAMENTO DE AÇOS IF, HSLA E DUAL PHASE*
}

\section{Resumo}

Jetson Lemos Ferreira ${ }^{1}$ José Osvaldo Amaral Tepedino² Marco Antonio Wolff

A necessidade de redução de espessura de componentes automotivos para atender a demanda por veículos mais leves, aliada ao aumento da complexidade geométrica das peças, tem exigido a utilização de aços de maior resistência e com boa conformabilidade. No entanto, a baixa capacidade de flangeamento dos aços de alta resistência limita a aplicação destes materiais em peças de geometrias mais complexas. O método de corte dos blanks tem influência decisiva na capacidade de flangeamento desses aços, que é avaliada em laboratório por ensaios de expansão de furo. Foi avaliado o efeito da folga de corte por cisalhamento e da qualidade da superfície de bordas puncionadas na capacidade de expansão de furo de aços Interstitial Free, High Strength Low Alloy e Dual Phase. Os resultados indicaram que para o aço IF, folgas entre $10 \%$ e $20 \%$ da espessura e que propiciaram bordas de corte dos tipos 2 e 3, segundo a classificação do ASM Handbook, foram as que geraram maior expansão de furo. A maximização da flangeabilidade foi conseguida para as folgas de corte de aproximadamente 15\% (bordas de corte tipos 3 e 4) para os aços DP e em torno de $20 \%$ (bordas tipos 2 e 3 ) para os aços HSLA.

Palavras-chave: Flangeamento; Expansão de furo; Borda de corte.

\section{EVALUATION OF THE SHEAR CUTTING EFFECT IN STRETCH FLANGEABILITY OF IF, HSLA AND DUAL PHASE STEELS}

\begin{abstract}
The necessity to reduce the thickness of automotive components to meet the demand for lighter vehicles, combined with the increase of the geometric complexity of the stamping parts, has required the use of higher strength steels with good formability. However, the lower stretch flangeability of the high strength steels limits the application of these materials in parts of more complex geometries. The method of cutting blanks has decisive influence on the ability to stretch the cut edges, which is measured at laboratory by hole expansion tests. The effect of cutting clearence and of punching edges quality surface on the hole expansion capacity of different steels, Interstitial Free, High Strength Low Alloy and Dual Phase was evaluated. The results indicated that the IF steel, with clearances between $10 \%$ and $20 \%$ of the thickness and that provided cutting edges of the types 2 and 3 according to the ASM Handbook classification, were those which produced the higher hole expansion capacity. The maximization of flangeability was achieved in clearences of approximately $15 \%$ (cutting edges types 3 and 4) for the DP steels and around 20\% (edge types 2 and 3 ) for HSLA steels.
\end{abstract}

Keywords: Flangeability; Hole expansion; Cutting edges.

Engenheiro Metalúrgico, M.Sc., Pesquisador, Centro de Tecnologia Usiminas, Ipatinga, MG, Brasil Engenheiro Metalúrgico, Pesquisador, Centro de Tecnologia Usiminas, Ipatinga, MG, Brasil.

Engenheiro Mecânico, M.Sc., Pesquisador, Centro de Tecnologia Usiminas, Ipatinga, MG, Brasil. * Contribuição técnica ao $51^{\circ}$ Seminário de Laminação - Processos e Produtos Laminados e
Revestidos, 28 a 31 de outubro de 2014, Foz do Iguaçu, PR, Brasil. 


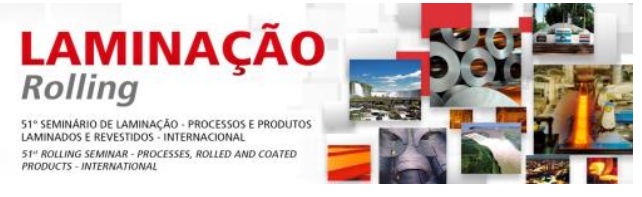

\section{INTRODUÇÃO}

\subsection{Corte por cisalhamento (puncionamento)}

O processo de corte por cisalhamento gera quatro zonas distintas na borda do material [1]. O material é inicialmente dobrado, gerando a zona de repuxo (indentação), e depois cisalhado até uma parcela da espessura. Finalmente, o material é rompido, propiciando a formação das zonas de fratura (estouro) e de rebarba, que apresentam uma inclinação em relação à zona cisalhada, expressa pelo ângulo de fratura, Figura 1.
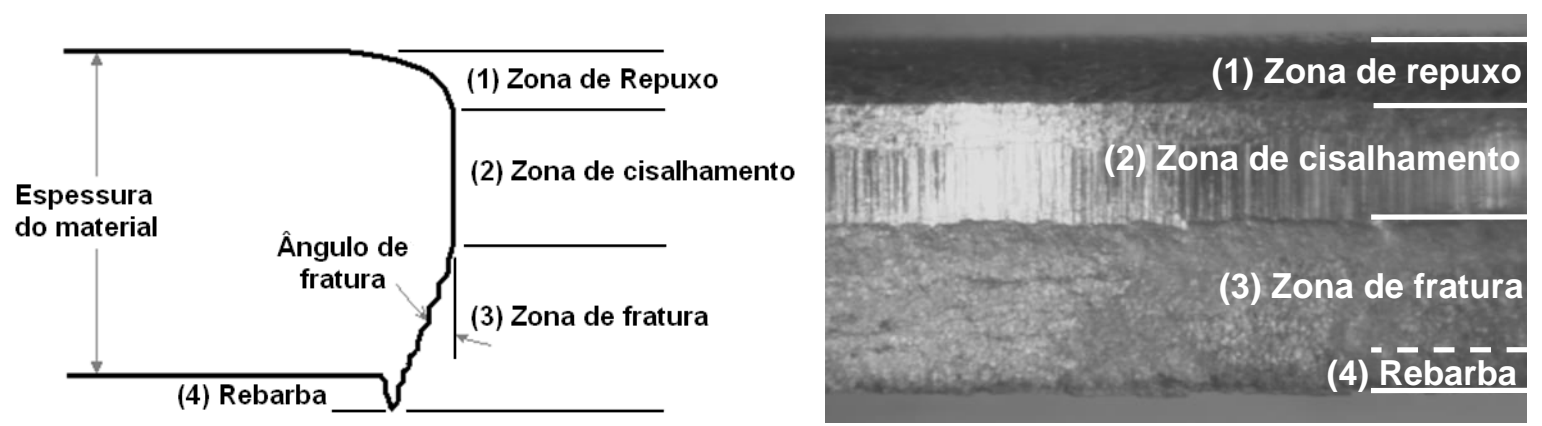

Figura 1. Representações ilustrativas das zonas em uma superfície de corte [1].

No caso de corte por puncionamento de furos circulares, a folga é dada pela metade da diferença entre os diâmetros da matriz $\left(d_{m}\right)$ e do punção $\left(d_{p}\right)$ dividida pela espessura do material (e), Equação 1.

$$
\text { Folga de corte }(\%)=\frac{\left(d_{m}-d_{p}\right)}{2 e} \times 100
$$

As dimensões das quatro zonas mostradas na figura 1 dependem da folga de corte empregada, não sendo encontradas em literatura tabelas ou fórmulas matemáticas que definam uma folga ótima para todas as situações de aplicações práticas. Segundo o ASM Handbook [2], a determinação da melhor qualidade de corte deve ser feita por "tentativa e erro", utilizando-se diferentes folgas até que se estabeleça a mais adequada para a aplicação específica. A Figura 2 apresenta os tipos de aspecto de bordas de corte (de 1 a 5 ) resultantes do emprego de diferentes folgas.
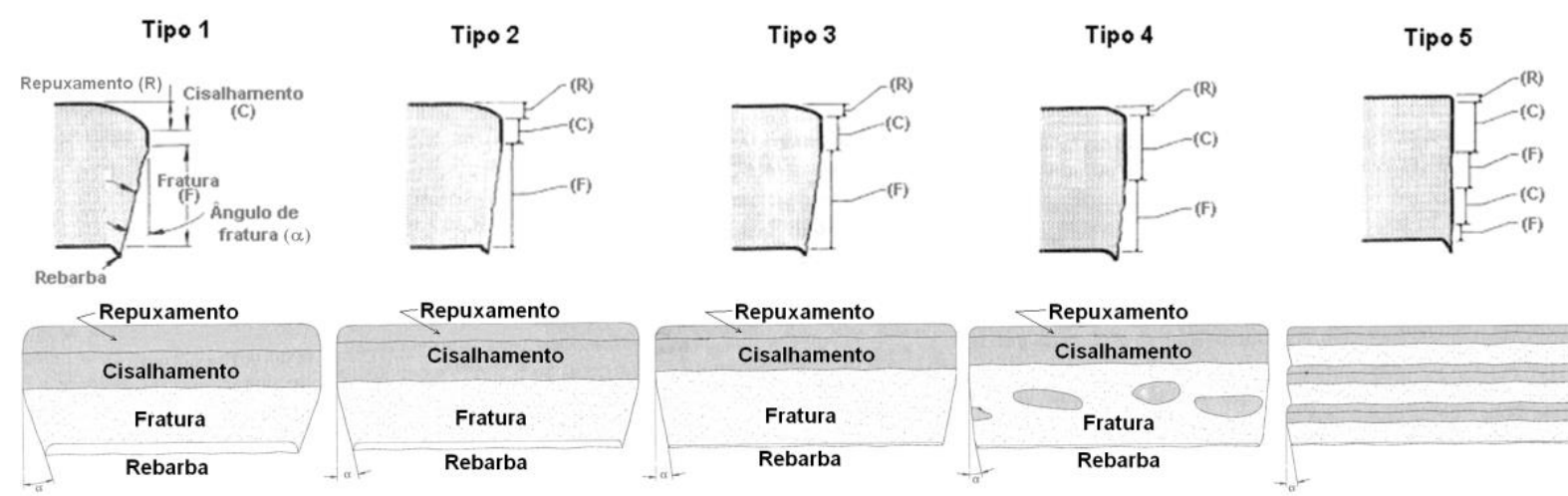

Figura 2. Efeito da folga matriz/punção nas características das bordas de corte [2].

Devido ao fato das folgas no puncionamento normalmente serem pequenas, da ordem de 5 a $20 \%$, é usual admitir-se que o corte se processa através de tensões cisalhantes que se distribuem pela espessura da peça ao longo do perímetro do contorno de corte. A deformação decorrente do estado de tensão por cisalhamento puro, característico do corte por puncionamento, pode ser visualizada na Figura 3,

* Contribuição técnica ao $51^{\circ}$ Seminário de Laminação - Processos e Produtos Laminados e Revestidos, 28 a 31 de outubro de 2014, Foz do Iguaçu, PR, Brasil. 


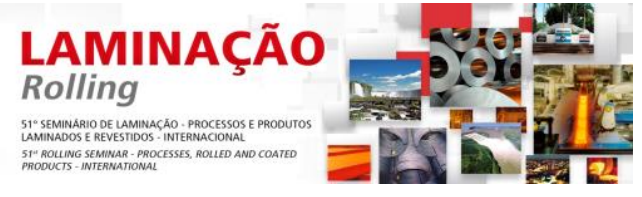

na qual se identifica a região da folga por ABCD. Pela ação das tensões cisalhantes, o material desta região se distorce progressivamente, acompanhando o avanço do punção, AA'. Para uma mesma penetração do punção, a distorção $\gamma$, dada por AA'/AC, aumenta com a diminuição da folga [3]. Esgotada a capacidade de deformação plástica do material, pelo aumento de tensão resultante da diminuição da seção resistente, surgem condições para se iniciar um mecanismo de fratura, que irá permitir a separação da peça. O início do mecanismo de fissuração depende

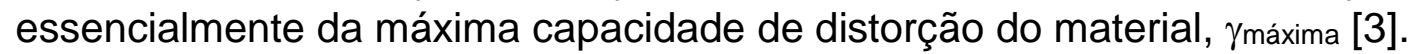

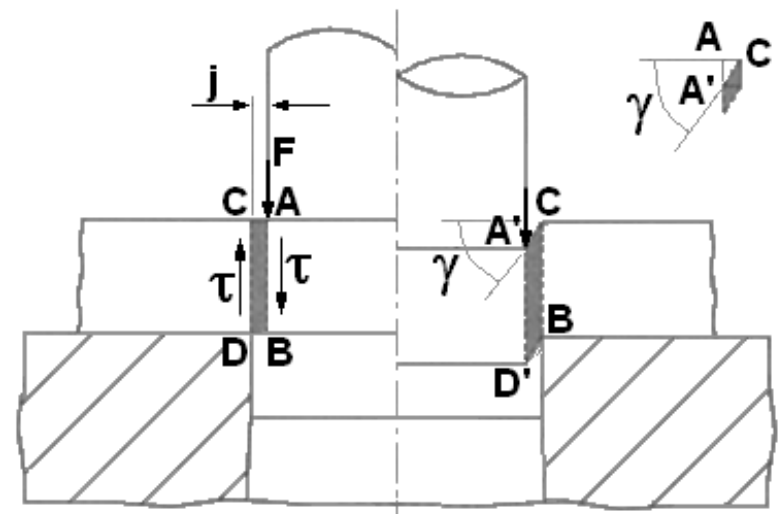

Figura 3. Representação da folga radial (j) existente entre o punção e a matriz e da distorção $(\gamma)$,resultante da ação das tensões de corte que atuam na região da folga, ABCD [3].

A evolução da força durante o processo de corte, mostrada esquematicamente na Figura 4, é função da diminuição da seção resistente e do encruamento propiciado pela deformação, que ocorrem durante a formação das zonas de repuxamento e de cisalhamento. O primeiro fator tende a diminuir a força cortante e o segundo tende a aumentá-la. No início do processo, o efeito do encruamento é maior, razão pela qual a força de corte aumenta progressivamente até seu valor máximo. A partir desse ponto, o efeito da redução de seção passa a ser preponderante e o material começa a se romper. Nota-se que a força aumenta até a completa formação da zona de cisalhamento, caindo com a formação da zona de fratura. A inflexão observada na queda da curva de força durante a fratura deve-se ao esforço necessário para vencer o atrito entre o "refugo do corte" e as paredes da matriz e entre o punção e as paredes do furo [3].

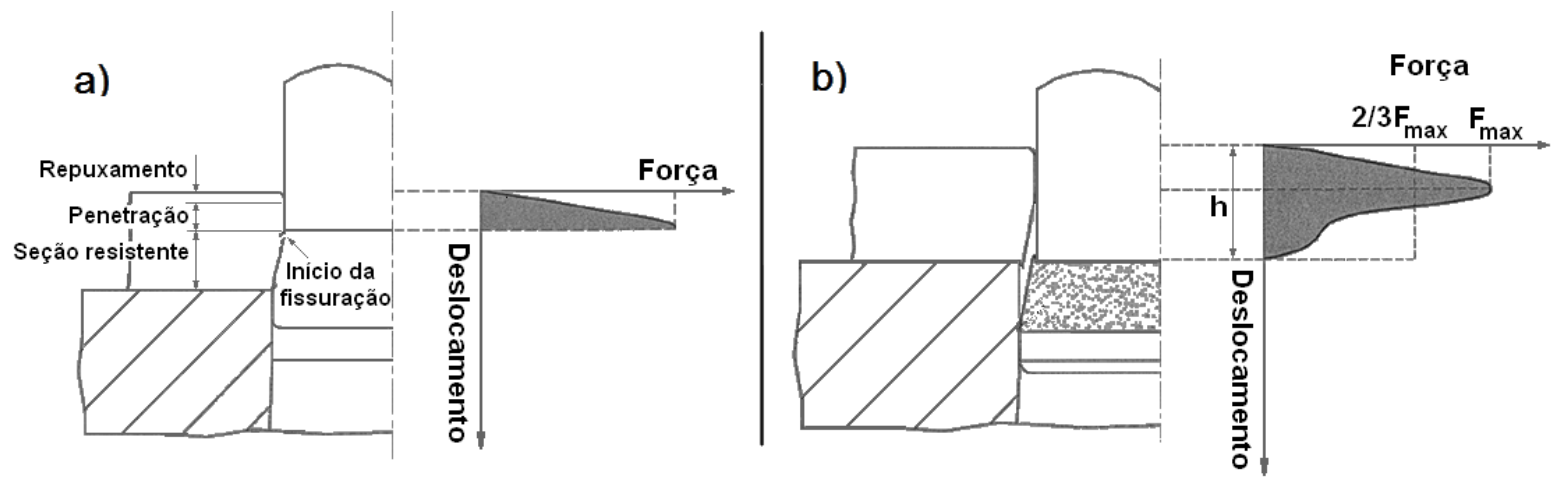

Figura 4. Evolução da força de corte com o deslocamento do punção: a) durante as fases de repuxamento e cisalhamento e b) após a fase de fratura [3].

A força máxima de corte ( $\left.F_{\text {máxima}}\right)$ pode ser estimada pelo produto da tensão cisalhante de corte $\left(\tau_{\text {corte}}\right)$ do material e a área da seção resistente ( $\pi$.D.e), Equação 2. Na qual, e é a espessura e D o diâmetro do furo. Como normalmente se

* Contribuição técnica ao $51^{\circ}$ Seminário de Laminação - Processos e Produtos Laminados e Revestidos, 28 a 31 de outubro de 2014, Foz do Iguaçu, PR, Brasil. 


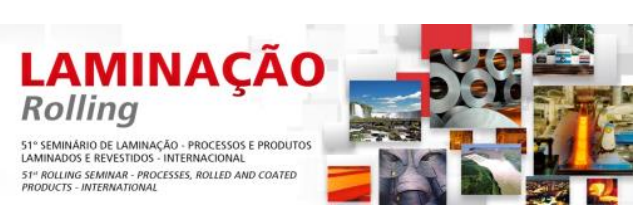

A força aplicada durante a confecção dos furos foi medida através da montagem do ferramental de corte em uma máquina universal Instron, modelo 5880.

Para a avaliação do encruamento gerado pelo puncionamento com diferentes folgas foram realizadas medições de dureza Vickers, com carga de $10 \mathrm{gf}$, em pontos próximos à borda de corte, conforme mostrado de forma esquemática na Figura 7.

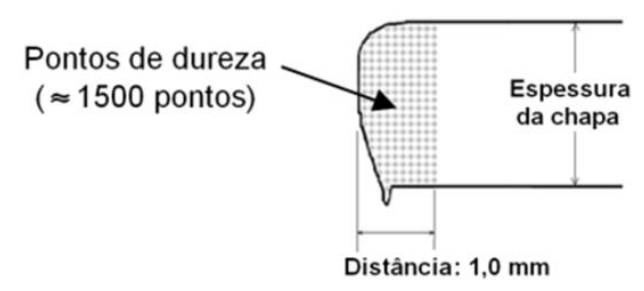

Figura 7. Representação esquemática dos locais onde foram realizadas as impressões de dureza Vickers na região adjacente à borda cortada por puncionamento com diferentes folgas.

\subsection{Ensaio de Expansão de Furo}

Para a avaliação da capacidade de flangeamento, foi empregado o ensaio de Expansão Cônica de Furo (ECF), que utiliza um punção de cabeça cônica $\left(60^{\circ}\right)$ para promover a expansão do furo de $10 \mathrm{~mm}$ de diâmetro, Figura 8. Os ensaios foram realizados em uma prensa hidráulica Erichsen, utilizando o descritivo da norma ISO TS 16630 [10] como referência. Cada ensaio foi interrompido imediatamente após a ocorrência de uma ou mais trincas atravessando toda a espessura do material na borda do furo. Os resultados dos ensaios foram expressos de acordo com a Equação 3.

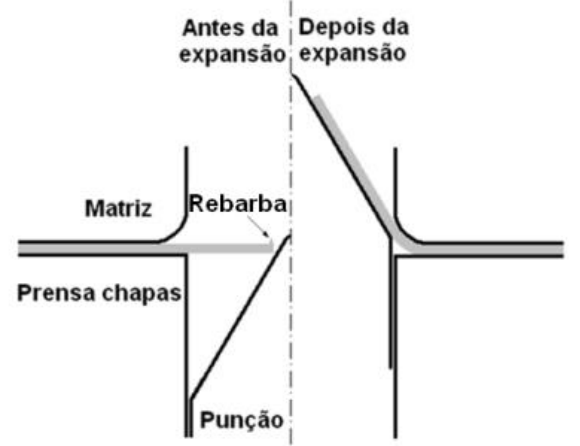

Figura 8. Esquema ilustrativo do ensaio de Expansão Cônica de Furo (ECF).

\section{RESULTADOS E DISCUSSÃO}

\subsection{Processo de Corte do Furo por Puncionamento}

Nas seções transversais à borda de corte das diferentes condições avaliadas podem ser observadas as zonas de repuxo, cisalhamento, fratura e rebarba. A variação do tamanho de cada uma das zonas, em relação à espessura, com a folga utilizada, para os aços IF, HSLA420 e DP800, é mostrada nas Figuras 9 e 10. De um modo geral, percebe-se que o tamanho das zonas de repuxo aumentou, enquanto que o da zona de cisalhamento diminuiu com a adoção de folgas de corte mais elevadas. As zonas de fratura e de rebarba aumentaram com a utilização de maiores folgas, notadamente nos aços de menor resistência, o mesmo acontecendo com o ângulo de fratura.

Os aços de menor resistência (IF, HSLA340 e DP450) foram os que apresentaram os maiores tamanhos de rebarba para folgas mais elevadas, enquanto os aços de

* Contribuição técnica ao $51^{\circ}$ Seminário de Laminação - Processos e Produtos Laminados e Revestidos, 28 a 31 de outubro de 2014, Foz do Iguaçu, PR, Brasil. 


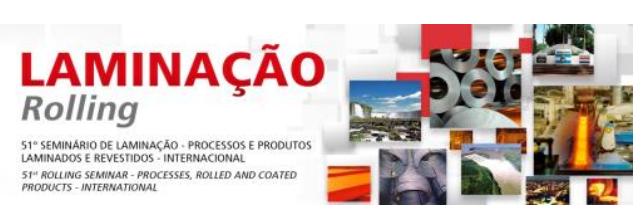

maior resistência (DP600, DP800 e DP1000) exibiram zonas de cisalhamento duplas para as menores folgas.

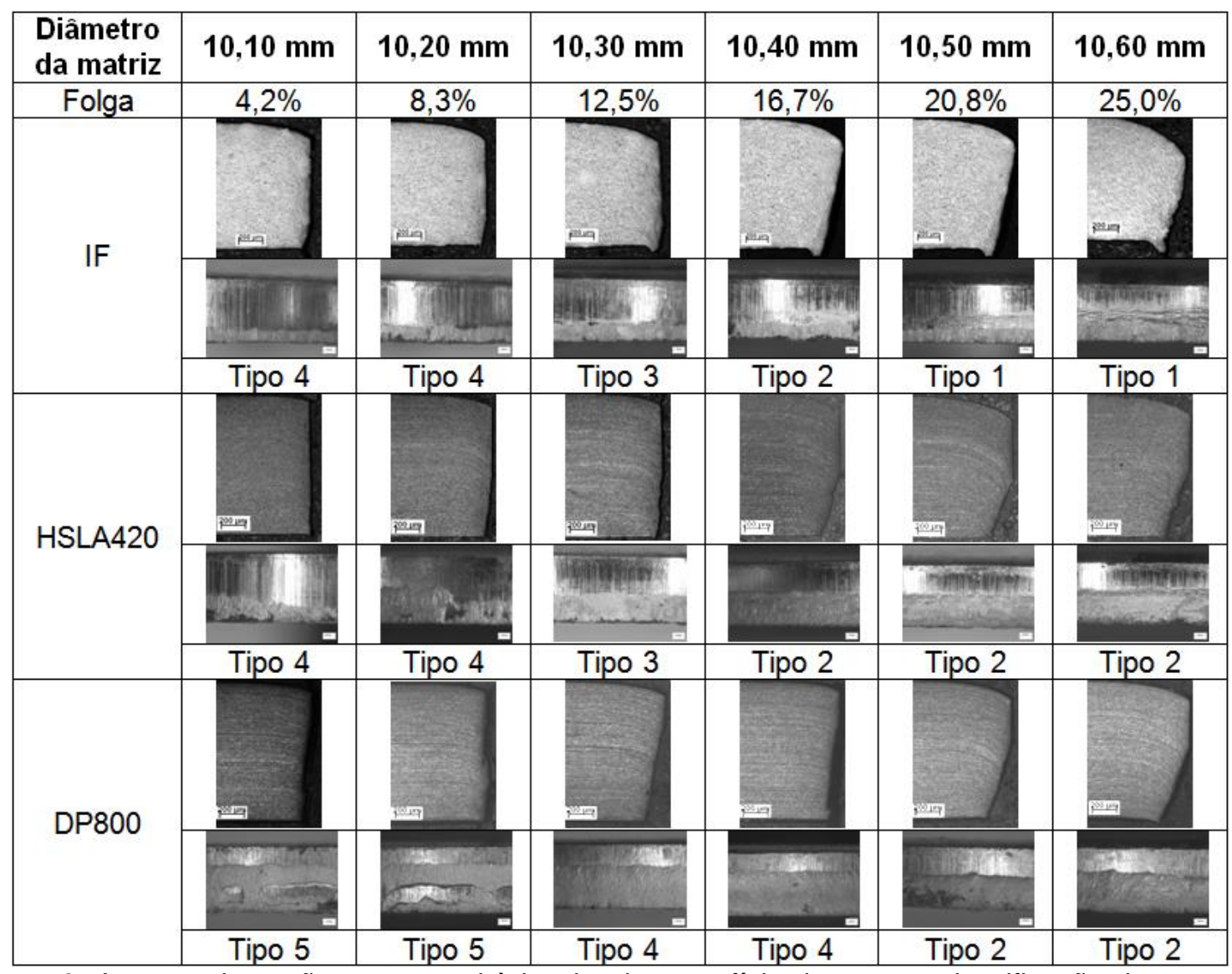

Figura 9. Aspecto da seção transversal à borda, da superfície de corte e classificação da operação de puncionamento para as diferentes folgas, segundo o ASM Handbook [2].
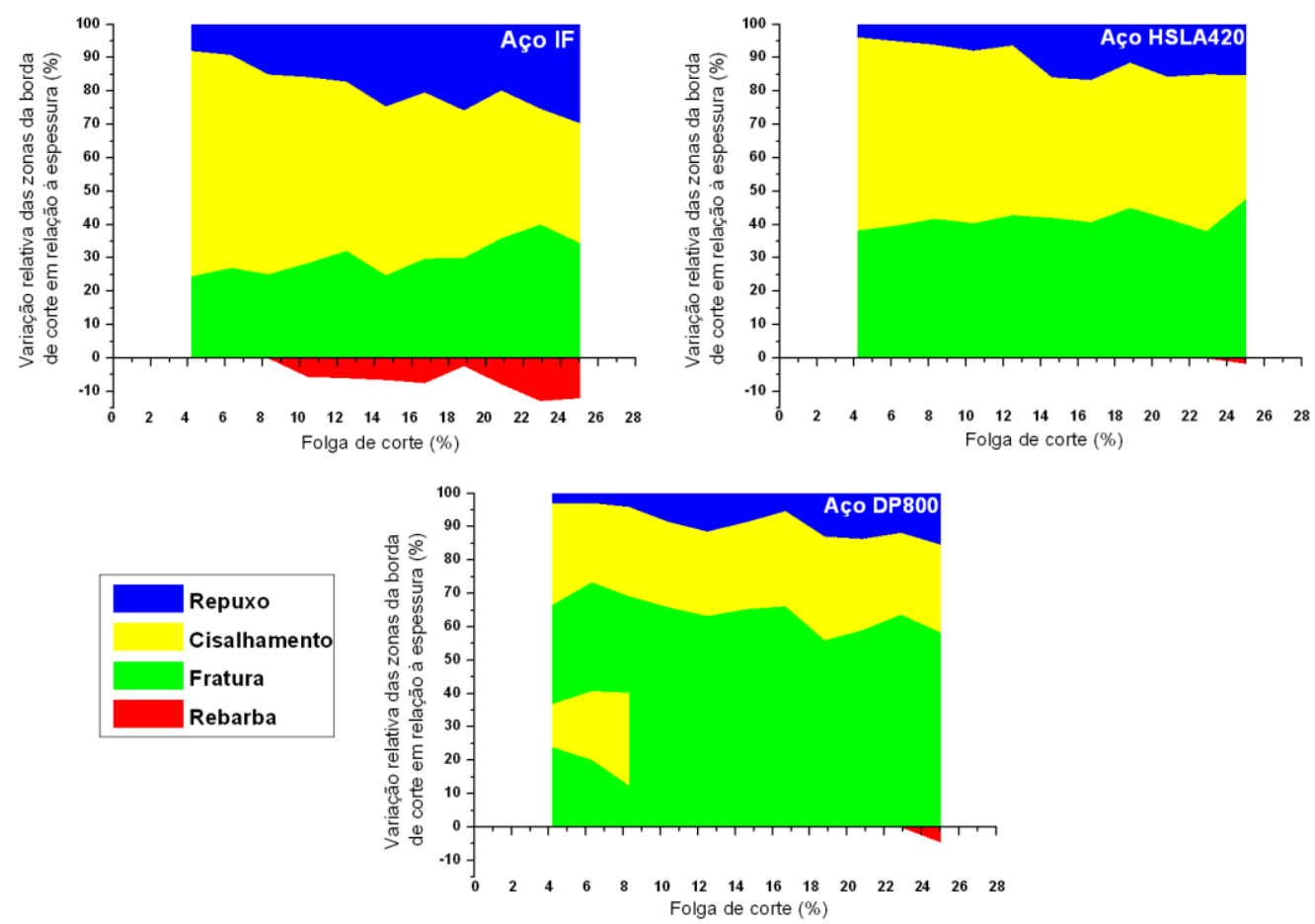

Figura 10. Composição percentual das zonas de corte, ao longo da espessura, para diferentes folgas empregadas nos aços IF, HSLA420 e DP800 avaliados.

* Contribuição técnica ao $51^{\circ}$ Seminário de Laminação - Processos e Produtos Laminados e Revestidos, 28 a 31 de outubro de 2014, Foz do Iguaçu, PR, Brasil. 


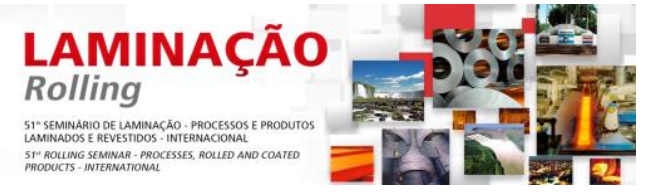

A região de estouro da borda de corte, segundo Milosevic e Moussy [1], é a que mais sofre deformação plástica durante a operação de corte, sendo o local de maior encruamento e, consequentemente, maior dureza da borda de corte. Na Figura 11 são mostrados mapeamentos de dureza da região adjacente à borda de corte dos furos confeccionados com folgas pequena $(4,2 \%)$, média $(12,5 \%$ seguindo a norma ISO TS 16630) [10] e grande (25\%). Observa-se que as escalas de dureza utilizadas para os materiais não foram as mesmas, pois avaliou-se aços com diferentes graus de resistência. Nota-se que, corroborando os resultados de Milosevic e Moussy [1], a zona de fratura foi a que apresentou a maior dureza. Percebe-se também que quanto menor a folga de corte empregada, menos extensa foi a região afetada pelo encruamento, indicada pelas cores vermelha, laranja e amarela.

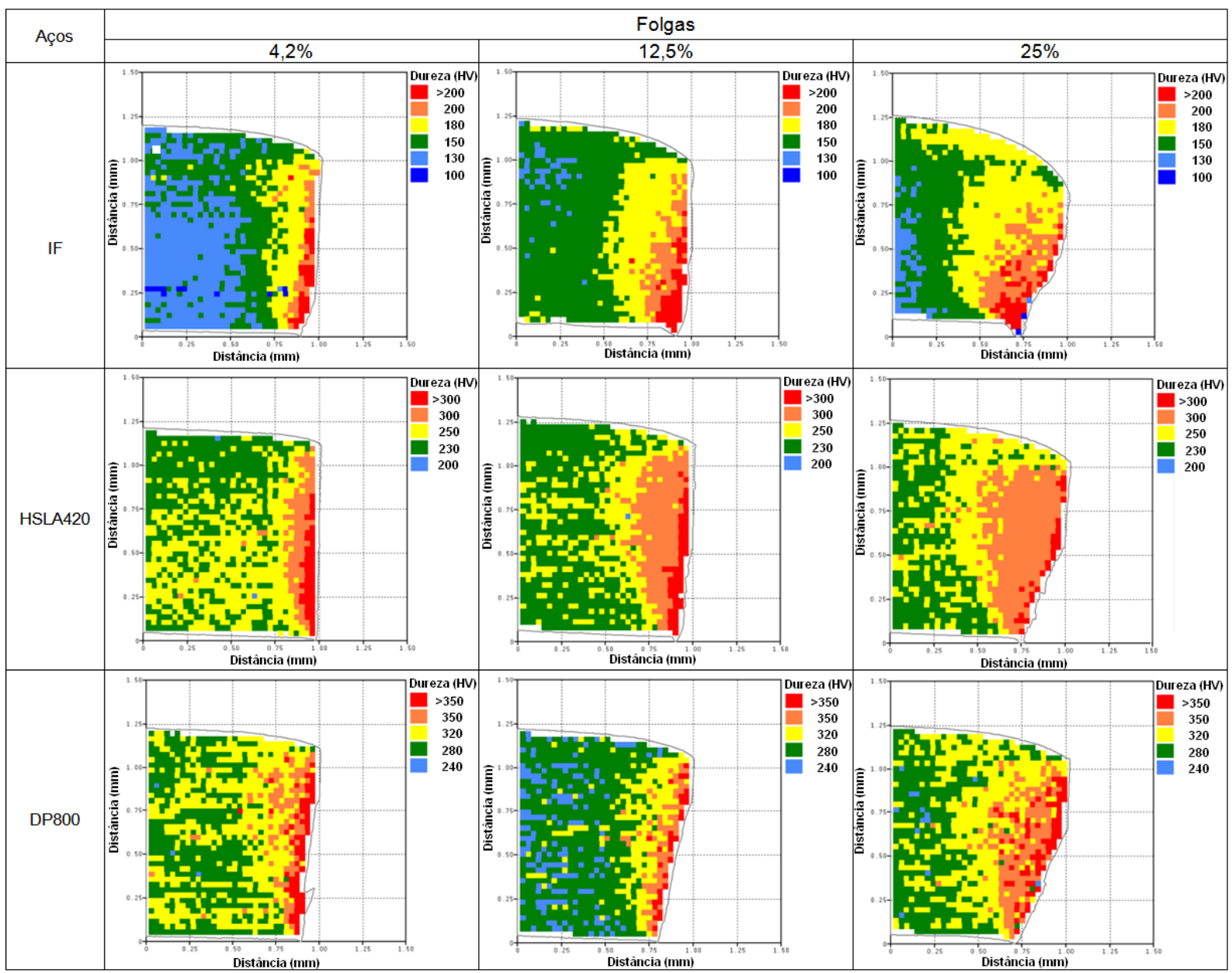

Figura 11. Perfil de dureza da borda de corte das amostras dos aços IF, HSLA420 e DP800 avaliados, que foram submetidos a corte por puncionamento com folgas de $4,2 \%, 12,5 \%$ e $25 \%$.

$\mathrm{Na}$ Figura 12 é mostrada a relação entre a distorção máxima dos materiais analisados e a folga de corte. A distorção máxima foi determinada pela razão entre 0 tamanho das zonas de repuxo e de cisalhamento e a folga de corte, tal como mostrado na relação AA'/AC da Figura 3. Nota-se que as menores folgas de corte, para todos os aços, foram as que resultaram em maiores distorções. A capacidade de distorção de todos os aços avaliados decresce de forma exponencial com o aumento da folga, tendendo a um valor constante de aproximadamente 2 . Os coeficientes das equações exponenciais ajustadas às curvas de distorção máxima também são mostradas na Figura 12.

* Contribuição técnica ao $51^{\circ}$ Seminário de Laminação - Processos e Produtos Laminados e Revestidos, 28 a 31 de outubro de 2014, Foz do Iguaçu, PR, Brasil. 

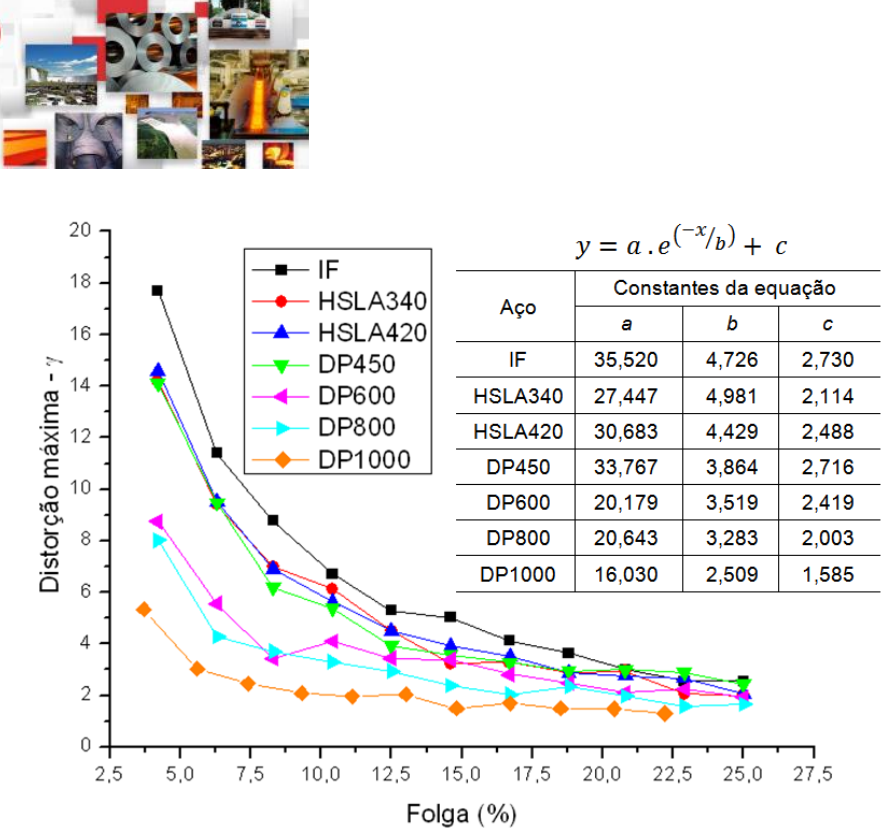

Figura 12. Relação entre a distorção $(\gamma)$ máxima e a folga de corte empregada nos aços avaliados.

A evolução da força de corte com o deslocamento do punção para os materiais avaliados, na condição de folga especificada na norma ISO TS 16630 [10] é mostrada na Figura 13. Nessa figura podem ser vistos também os valores da constante $C$ da Equação 2, dado pela razão entre a tensão máxima de corte e o limite de resistência, para os materiais puncionados nas diferentes folgas de corte avaliadas. Os valores de $\mathrm{C}$ obtidos, coerentes com relatos de literatura [2,3], diminuíram com o aumento do limite de resistência do aço e da folga de corte (maior diâmetro da matriz).

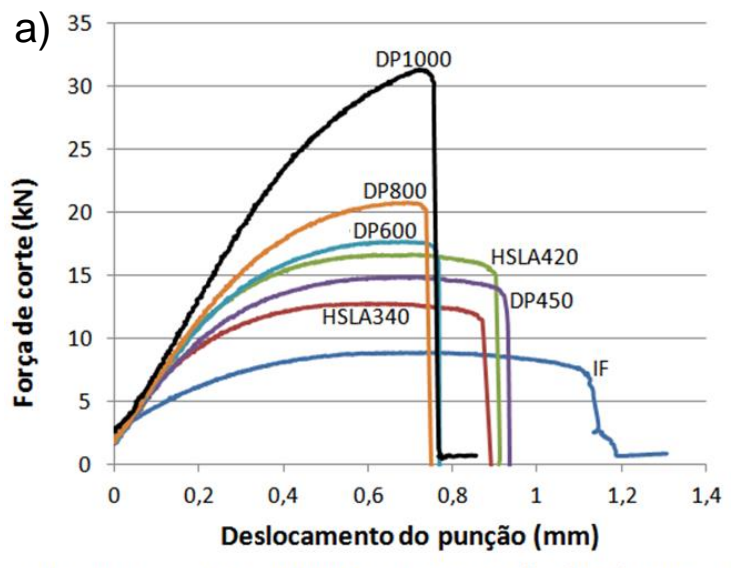

b) Valores da constante $\mathrm{C}$ que relaciona a tensão máxima de corte e o limite de resistência à tração uniaxial

\begin{tabular}{c|c|c|c}
\hline Aços & $\phi$ Matriz 10,1 mm & $\phi$ Matriz 10,3 mm & $\phi$ Matriz 10,6 mm \\
\hline IF & 0,84 & 0,80 & 0,80 \\
\hline HSLA340 & 0,78 & 0,75 & 0,76 \\
\hline HSLA420 & 0,75 & 0,73 & 0,73 \\
\hline DP450 & 0,80 & 0,78 & 0,78 \\
\hline DP600 & 0,80 & 0,76 & 0,75 \\
\hline DP800 & 0,78 & 0,73 & 0,72 \\
\hline DP1000 & 0,71 & 0,71 & 0,69
\end{tabular}

Obs.: Espessura do aço DP1000 é $1,35 \mathrm{~mm}$ e dos demais $1,2 \mathrm{~mm}$

Figura 13. a) Curvas de força de corte $x$ deslocamento do punção nas diferentes folgas de corte empregadas para os aços avaliados. b) Relação entre a tensão máxima de corte e o limite de resistência à tração uniaxial para cada aço, em três condições de folga avaliadas.

$\mathrm{Na}$ Figura 14 são mostradas as comparações entre a tensão de corte dos aços avaliados, em termos de valores absolutos e relativos, tendo como referência o desempenho do aço IF, para condições de folgas pequena, de acordo com a norma ISO TS 16630 [10] e grande. Esse aço foi utilizado como referência devido ao fato de suas condições de corte serem bastante conhecidas pela indústria metal mecânica. Nota-se que, independente da folga utilizada, a tensão de corte do aço DP1000 foi cerca de 3 vezes maior que a do IF, a do DP800 foi aproximadamente 2,2 vezes maior, a dos materiais DP600 e HSLA420 cerca de 2 vezes maior e a dos aços DP450 e HSLA340 em torno de 1,5 vezes mais elevada do que a do IF.

* Contribuição técnica ao $51^{\circ}$ Seminário de Laminação - Processos e Produtos Laminados e Revestidos, 28 a 31 de outubro de 2014, Foz do Iguaçu, PR, Brasil. 

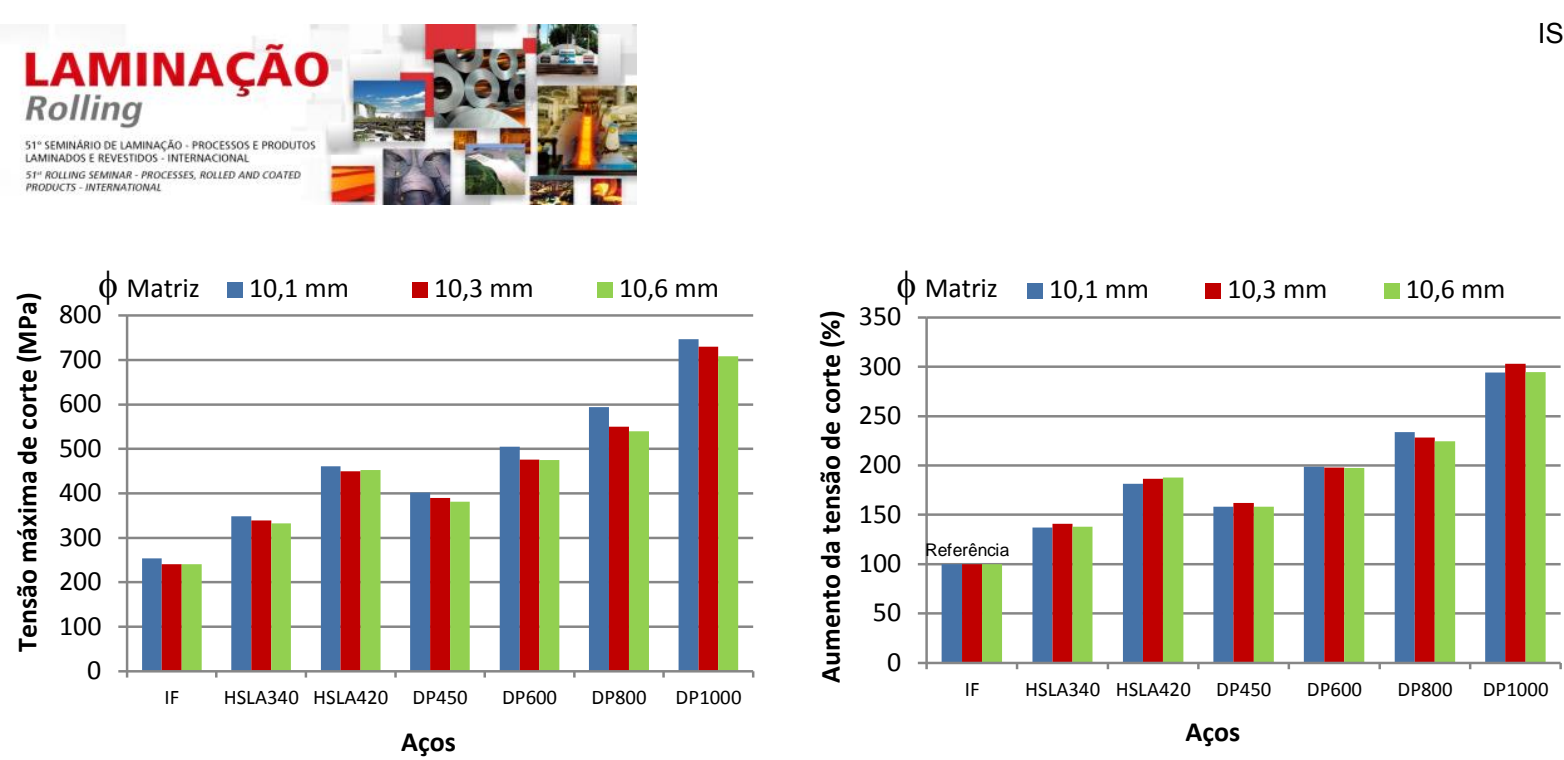

Figura 14. Variação dos valores absolutos e relativos de tensão máxima de corte dos aços avaliados, tendo como referência o valor obtido para o aço IF.

\subsection{Efeito da Folga de Corte na Capacidade de Expansão de Furo}

Os resultados dos ensaios de expansão cônica de furo, expressos pelo valor $\lambda$, para as diferentes folgas de corte empregadas, são mostrados na figura 15. Percebe-se que o aço IF (Figura 15.a) apresentou uma capacidade de expansão de furo bem superior à dos demais aços, exigindo inclusive um gráfico com escala diferente dos outros. Ele foi o único aço que mostrou elevada sensibilidade à alteração da folga de corte, sendo que folgas entre $10 \%$ e $20 \%$ geraram bordas de corte dos tipos 2 e 3 , segundo a classificação feita pelo ASM Handbook [2], figura 2.

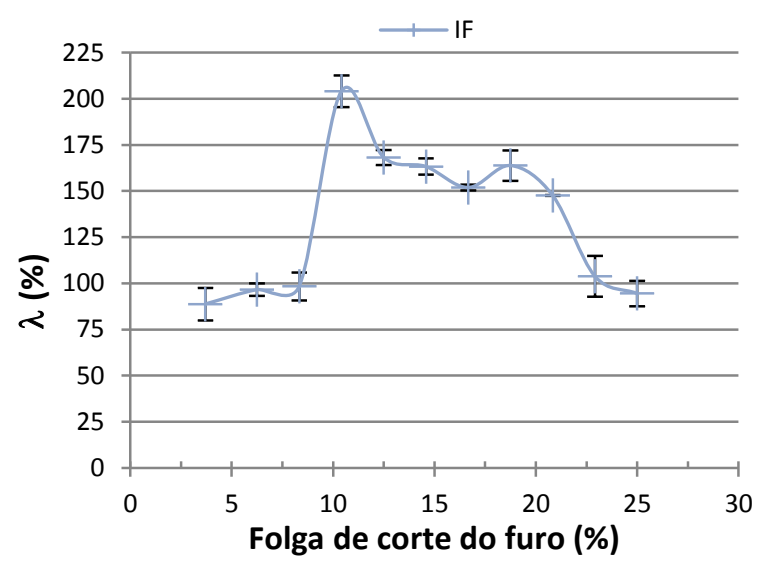

a) Aço Interstitial free

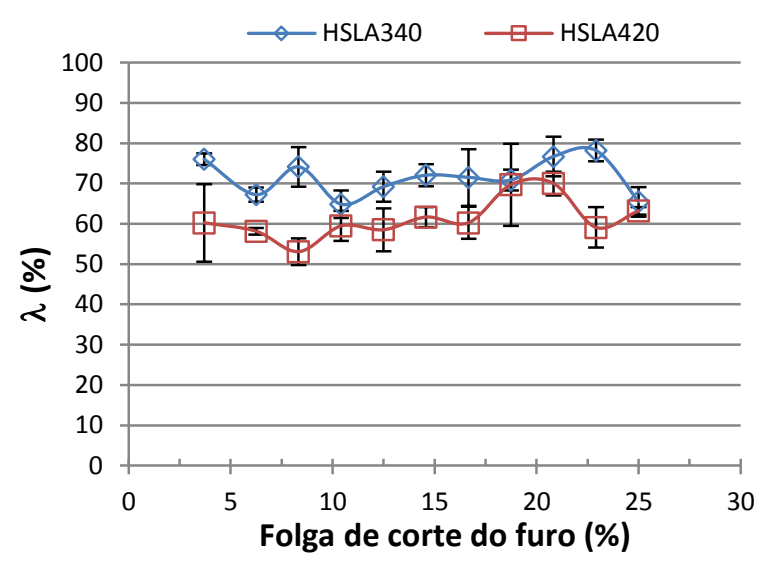

b) Aços HSLA

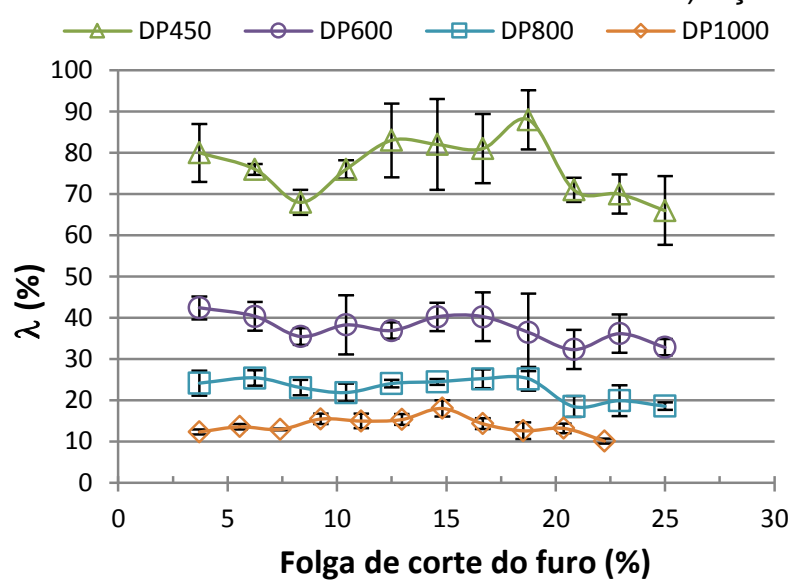

c) Aços Dual Phase

Figura 15. Variação da capacidade de expansão de furo em função da folga de corte empregada nos aços avaliados.

* Contribuição técnica ao $51^{\circ}$ Seminário de Laminação - Processos e Produtos Laminados e Revestidos, 28 a 31 de outubro de 2014, Foz do Iguaçu, PR, Brasil. 


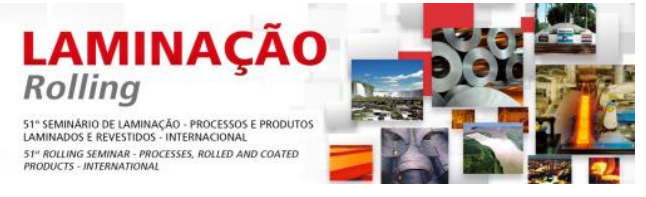

Os aços HSLA340 e HSLA420 apresentaram capacidades de expansão de furo, respectivamente, de $65 \%$ a $78 \%$ e de $53 \%$ a $70 \%$, Figura 15.b. Nota-se que não houve, para esses aços, uma tendência clara entre a variação da capacidade de expansão de furo e a folga de corte, ao contrário do aço IF. Folgas em torno de $20 \%$, que geraram bordas de corte do tipo 2, foram as mais adequadas para os aços HSLA.

A capacidade de flangeamento dos acos Dual Phase (Figura 15.c) variou de forma inversamente propocional com a classe de resistência desses materiais, como era de se esperar. Para o aço DP450, as folgas compreendidas entre $10 \%$ e $20 \%$ (bordas dos tipos 2 e 3 ) foram as que exibiram os melhores resultados. Os aços DP600 e DP800 apresentaram maior flangeabilidade nas menores folgas (borda tipo 5) e em torno de 15\% (borda tipo 3). Vale ressaltar que bordas de corte do tipo 5 são geradas por folgas bastante pequenas e resultam em forças de corte elevadas, que podem prejudicar as ferramentas de forma prematura. O aço DP1000 foi o que apresentou os menores resultados de $\lambda$. Para esse aço, a borda de corte que resultou na melhor capacidade de estiramento de flange foi a do tipo 4, gerada por folga de corte de $15 \%$. A condição de borda que exibiu os piores resultados em termos de flangeabilidade pelo ensaio de expansão cônica de furo para os aços Dual Phase de maior resistência foi a do tipo 2.

$\mathrm{Na}$ Tabela 2 são mostradas as folgas e as borda de corte que resultaram em maior capacidade de estiramento de flange dos materiais avaliados. Os valores mostrados nessa tabela encontram-se em consonância com os resultados obtidos por Abe [8] e Konieczny e Henderson [9] (Figura 6).

Tabela 2. Valores de folga e tipos de borda de corte que resultaram em maior capacidade de estiramento de flange nos materiais avaliados.

\begin{tabular}{c|c|c|c}
\hline Aço & Folgas (\%) & Tipo de borda de corte & $\lambda(\%)$ \\
\hline IF & $10 \mathrm{a} 20$ & $2 \mathrm{e} 3$ & $148 \mathrm{a} 204$ \\
\hline HSLA340 & $\approx 20$ & 2 & $\approx 75$ \\
\hline HSLA420 & $\approx 20$ & 2 & $\approx 70$ \\
\hline DP450 & $10 \mathrm{a} 20$ & $2 \mathrm{e} \mathrm{3}$ & $81 \mathrm{a} 88$ \\
\hline DP600 & $\approx 15$ & 3 & $\approx 40$ \\
\hline DP800 & $15 \mathrm{a} 18$ & 3 & $\approx 25$ \\
\hline DP1000 & $\approx 15$ & 4 & $\approx 18$ \\
\hline
\end{tabular}

\section{CONCLUSÃO}

Verificou-se pelos aspectos das bordas de corte das amostras analisadas que as classificadas como tipo 5, segundo o ASM Handbook [2], foram observadas somente nos aços mais resistentes (DP600, DP800 e DP1000) e para pequenas folgas de corte. Enquanto que as bordas de corte do tipo 1 (propiciadas pelas maiores folgas) só ocorreram nos aços mais macios (IF, HSLA340 e DP450). Os demais tipos de borda de corte (2, 3 e 4) da classificação ASM Handbook [2] foram observados em todos os materiais avaliados para as folgas utilizadas.

Observou-se que o tamanho das zonas de corte depende do grau dos aços, sendo que quanto mais elevada a resistência, menor foi, para uma mesma folga, o tamanho das zonas de repuxo e de cisalhamento, ou seja, menor foi a capacidade de distorção desses materiais. Nos materiais mais resistentes, observou-se a ocorrência de dupla zona de cisalhamento, enquanto que nos mais macios foram constatados maiores tamanhos de rebarba.

\footnotetext{
* Contribuição técnica ao $51^{\circ}$ Seminário de Laminação - Processos e Produtos Laminados e Revestidos, 28 a 31 de outubro de 2014, Foz do Iguaçu, PR, Brasil.
} 


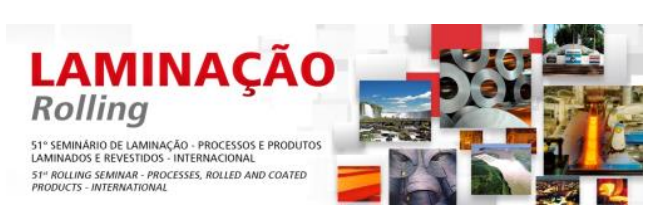

A força de corte variou inversamente com a folga utilizada e diretamente com o limite de resistência em tração dos aços. A relação obtida entre a tensão de corte e o limite de resistência em tração uniaxial variou entre 0,7 e 0,8, corroborando dados de literatura [2,3].

Por meio da comparação das tensões de corte dos materiais avaliados em relação à do aço IF, pode-se afirmar que a do DP1000 foi em torno de 3 vezes maior, a do DP800 foi aproximadamente 2,2 maior, a dos materiais DP600 e HSLA420 cerca de 2 vezes maior e a dos aços DP450 e HSLA340 em torno de 1,5 vezes mais elevada. Verificou-se que a capacidade de expansão de furo do aço IF exibiu uma dependência com a folga de corte bem maior do que a dos demais aços. Folgas entre $10 \%$ e $20 \%$, que geraram bordas de corte dos tipos 2 e 3 , foram as que resultaram nos maiores valores de expansão de furo para o aço IF. De um modo geral, para os aços Dual Phase e HSLA, a maximização da flangeabilidade foi conseguida nas folgas de corte de aproximadamente 15\% (bordas dos tipos 3 e 4) e em torno de $20 \%$ (bordas dos tipos 2 e 3 ), respectivamente.

\section{REFERÊNCIAS}

1 Milosevic Z, Moussy F. Simulation of sheared edge behavior in stretch flanging by a modified Fukui test. Advanced Technology of Plasticity, 1987, Vol. II, 697-702 pp.

2 ASM International Handbook. Forming and forging - Section: blanking and piercing of steel sheet, strip and plate. Vol.14, 27-49 pp.

3 Rodrigues J, Martins P. Tecnologia mecânica: tecnologia da deformação plástica: aplicações industriais. Lisboa: Escolar Editora, 2005, Vol. 2, 742 pp.

4 Automotive Applications Committe. Flanging. American Iron and Steel Institute IISI, 03/2004.

5 Wang CT, Kinzel G, Altan T. Failure and wrinkling criteria and mathematical modeling of shrink and stretch flanging operation in sheet-metal forming. Journal of Materials Process Technology, 1995, 759-780 pp.

6 Smith \& Associates. Forming flanges and process limitations. 06/2003, 1-12 pp.

7 Sriram S, Chintamani J. Guidelines for stretch flanging advanced high strength steels. American Iron and Steel Institute of Physics, 2005, 681-686 pp.

8 Sadagopan $S$, et al. Formability characterization of a new generation of high strength steels. American Iron and Steel Institute, AISI, 05/2003, 1-156 pp.

9 Abe Y. Melhoria da flangeabilidade de aços de alta resistência. Apresentação técnica da Universidade Japonesa Tokayashi Technical Science University.

10 ISO/TS16630. Metallic materials - Method of hole expanding test. Technical Specification, 2003.

* Contribuição técnica ao $51^{\circ}$ Seminário de Laminação - Processos e Produtos Laminados e Revestidos, 28 a 31 de outubro de 2014, Foz do Iguaçu, PR, Brasil. 